\title{
Antimicrobial Properties of Silver Nitrate Nanoparticle and Its Application in Endodontics and Dentistry: A Review of Literature
}

\author{
Lakshmi Thangavelu $\mathbb{D D}^{1},{ }^{1}$ Abdul Habeeb Adil, ${ }^{2}$ Sohaib Arshad, ${ }^{3}$ Ezhilarasan Devaraj ${ }^{D},{ }^{1}$ \\ Sreekanth Kumar Mallineni $\mathbb{D}^{4,5}$ Rishitha Sajja, ${ }^{6}$ Anil Chakradhar $\mathbb{D}^{1}{ }^{7}$ \\ and Mohmed Isaqali Karobari $\mathbb{1}^{8,9}$
}

\footnotetext{
${ }^{1}$ Department of Pharmacology, Saveetha Dental College and Hospital, Saveetha Institute of Medical and Technical Sciences, Saveetha University, Chennai, India

${ }^{2}$ Department of Community Dentistry, School of Dental Sciences, Health Campus, Universiti Sains Malaysia, Kubang Kerian, 16150 Kota Bharu, Kelantan, Malaysia

${ }^{3}$ Periodontics Unit, School of Dental Sciences, Health Campus, Universiti Sains Malaysia, Kubang Kerian, 16150 Kota Bharu, Kelantan, Malaysia

${ }^{4}$ Department of Preventive Dental Science, College of Dentistry, Majmaah University, Al-Majmaah, Saudi Arabia

${ }^{5}$ Department of Pediatric Dentistry, Saveetha Dental College and Hospital, Saveetha Institute of Medical and Technical Sciences, Saveetha University, Chennai, India

${ }^{6}$ Department of Research and Development, Bristol Myers Squibb, New Jersey, USA

${ }^{7}$ Department of Conservative Dentistry, Kathmandu University, Dhulikhel, Kavre, Nepal

${ }^{8}$ Conservative Dentistry Unit, School of Dental Sciences, Universiti Sains Malaysia, Health Campus, Kubang Kerian, Kota Bharu 16150, Kelantan, Malaysia

${ }^{9}$ Department of Conservative Dentistry \& Endodontics, Saveetha Dental College \& Hospitals, Saveetha Institute of Medical and Technical Sciences University, Chennai, 600077 Tamil Nadu, India
}

Correspondence should be addressed to Anil Chakradhar; anil254413@gmail.com and Mohmed Isaqali Karobari; dr.isaq@gmail.com

Received 18 August 2021; Accepted 17 September 2021; Published 9 November 2021

Academic Editor: Jianbo Yin

Copyright (C) 2021 Lakshmi Thangavelu et al. This is an open access article distributed under the Creative Commons Attribution License, which permits unrestricted use, distribution, and reproduction in any medium, provided the original work is properly cited.

Background. The silver nanoparticles (Ag NPs) are the most acceptable and excellent nanotechnology-based product among all metallic nanoparticles (noble metals). They are novel in terms of good conductivity, catalytic, chemical stability, and most significant anti-inflammatory and antiviral activities. Aim. This review is aimed at understanding the synthesis, mechanism, and applications of Ag NPs in dentistry and their qualities to aid clinicians and researchers. Materials and Methods. A electronic search for literature was performed on the Google Scholar, PubMed, EMBASE, and Web of Science databases for related articles using multiple keywords. The keywords used were antimicrobial properties, mechanism of action, and current uses of Ag NPs in dentistry. The search was limited to articles published in the English language; no deadline was set for publications. Results. About 185 articles were considered relevant to the reported research out of 6420 electronic search results. Only the publications that were required were received after all abstracts were assessed for relevance. After a final electronic and manual search, roughly 47 research publications were found to be helpful in this study. Conclusion. The Ag NPs, unlike other biomaterials used in dentistry, have unique biological features and could be used in endodontics, restorative dentistry, periodontology, prosthetic dentistry, implantology, and oral malignancies, because of their antimicrobial, antifungal, and antiviral effects. 


\section{Introduction}

It is important to investigate and assess antimicrobial substances with minimum toxicity to periapical tissues [1]. After careful shaping and cleaning of roots, the hermetic sealing of the root canal system is critical in endodontics. Through mechanical and chemical debridement, root canal therapy is aimed at eradicating microbes from the root canal system completely. Chemical debridement is linked with high success rates in bacterial elimination from the root canal system, whereas mechanical cleaning can minimize microorganisms in the root canal [2]. However, because it is impossible to eradicate all microorganisms from the root canal system throughout the treatment, endodontic materials must contain specific components that release antibacterial substances [3]. The most likely cause for this is the complex anatomy of the root canal system, which allows bacteria to colonize in inaccessible places to antimicrobial agents [4]. Despite cleaning, shaping, and administration of highly effective antimicrobial agents, clinical trials have shown that bacteria remain within the root canal system because bacteria can form biofilms, infiltrate dentinal tubules, and cause monoinfection $[5,6]$.

The prefix "nano" has been increasingly applied to various domains of knowledge throughout the previous decade. Nanotechnology is the science of the very small. It involves the use and manipulation of materials on a very small scale. The molecules and atoms behave differently at this dimension, allowing for several unexpected and fascinating applications [7]. The Ag NPs are highly acceptable and excellent nanotechnology-founded products among all metallic nanoparticles (noble metals). They are novel in terms of good conductivity, catalytic, chemical stability, and most significant anti-inflammatory and antiviral activities [8]. The Ag NPs and silver-incorporated compounds are proven very poisonous to microbes, with substantial biocidal properties upon as many as 16 bacteria species, comprising bacteria, fungi, and viruses [9]. The discharge of silver ions, which increases absorbency and causes injury to the bacterial DNA and cytoplasm, is responsible for the antibacterial activity. By interfering with the bacterial metabolism, the development of complexes between silver nanoparticles and proteins may result in bacterial mortality. The bacteriostatic effect may come from particle interaction with bacterial DNA, inhibiting cell multiplication [10]. Ag NPs with a $1-10 \mathrm{~nm}$ particle size bind to the cell surface with bacterial breakdowns, such as absorbency and oxygenation [11]. Nanoparticles are characterized as either naturally occurring or synthesized based on their composition. In nature, they are classified as organic or inorganic. They are categorized as particles, spheres, tubes, rods, plates, and so on based on their shape, as shown in Figure 1.

Although the antibacterial process of Ag NPs is yet unknown, several characteristics of their antimicrobial activity have been identified. Silver ions have the aptitude for interacting with the cell structures of many bacteria [12]. These silver ions appear to attach to the cytoplasmic membrane and cell wall primarily by electrostatic affinity and attractiveness for sulphur proteins, therefore increasing the absorbency of membrane and preceding the distraction of these structures. DNA, proteins, and lipids are among the bacterial components that Ag NPs can destroy. Silver nanoparticles also cause bacterial cell death by inducing an oxidative stress response. Bacteria in the mouth prefer to form biofilms, which provide excellent conditions for development, immune elusion, and antibiotic confrontation. The efficacy of nanoparticles in biofilm has an inverse connection with their size; nanoparticles larger than $50 \mathrm{~nm}$ cannot enter the biofilm because of their relative self-dispersal coefficients, which drop exponentially with the square of the nanoparticle diameter [13]. Furthermore, charged NPs do not readily disperse across the biofilm, owing to carboxyl groups and phosphoryl on the bacteria's surface, which provides the cell surface an electronegative character [14].

Since their debut, the use of nanoparticles in many disciplines of dentistry has increased dramatically because of the abovestated characteristics, mode of action, and advantages above other traditional materials. Nanotechnology has progressed, and the antibacterial capabilities of nanostructured silver-based formulations have been proven against fungi, bacteria, and viruses [15-18]. The Ag NPs were shown to have efficient antimicrobial constituents in adhesives [19], prosthetics materials [20], and in implants to enhance the arrest of caries, induce osteogenic induction, and inhibit biofilm development [21]. Nanomaterials have proven efficacy in biofilm development, enhancing tooth structure remineralization by preventing the removal of minerals and combating endodontic microorganisms. In endodontics, these NPs can be included in an intracanal medicament, obturating substance, irrigating solutions, and sealer [22]. As a result, it is realistic to expect Ag NPs to perform a significant role soon, especially in dentistry. With each passing year, the impact of nanoparticles in dentistry, for the treatment of various oral disorders grows exponentially.

Nanoparticles have been used in the development of new irrigation materials because of the drawbacks of conventional irrigants. The chitosan NPs were shown to have improved antibiofilm effectiveness and inhibit bacterial endotoxins [23]. Afkhami et al. compared $2.5 \%$ sodium hypochlorite with the irrigation qualities of $100 \mathrm{ppm} \mathrm{Ag}$ NPs in previous research and found that Ag NPs had more significant antibacterial activity. Furthermore, when related to sodium hypochlorite, polyvinyl-coated Ag NPs were shown to have lower cytotoxicity $[24,25]$. Due to their size, which lets infiltration into the canaliculus of the tooth, $\mathrm{Ag}$ NPs are viable for disinfection methods [26]. Therefore, these NPs-incorporated materials have immense ability to be employed as an intracanal medication and/or irrigating solution during endodontic treatment. Antimicrobial action was also observed against Streptococcus mutans, E. coli, E. faecalis, Actinomyces, and Candida albicans when mineral trioxide aggregate (MTA) and calcium-based cement were combined with Ag NP. Silver particles can help endodontic sealers to have better antibacterial qualities by reducing the adhesion of microorganism to the tooth surface $[27,28]$.

In the last three years, several significant studies on the uses of nanomaterials in dentistry were published, each with a distinct focus. However, the features of $\mathrm{Ag} \mathrm{NP}$ 


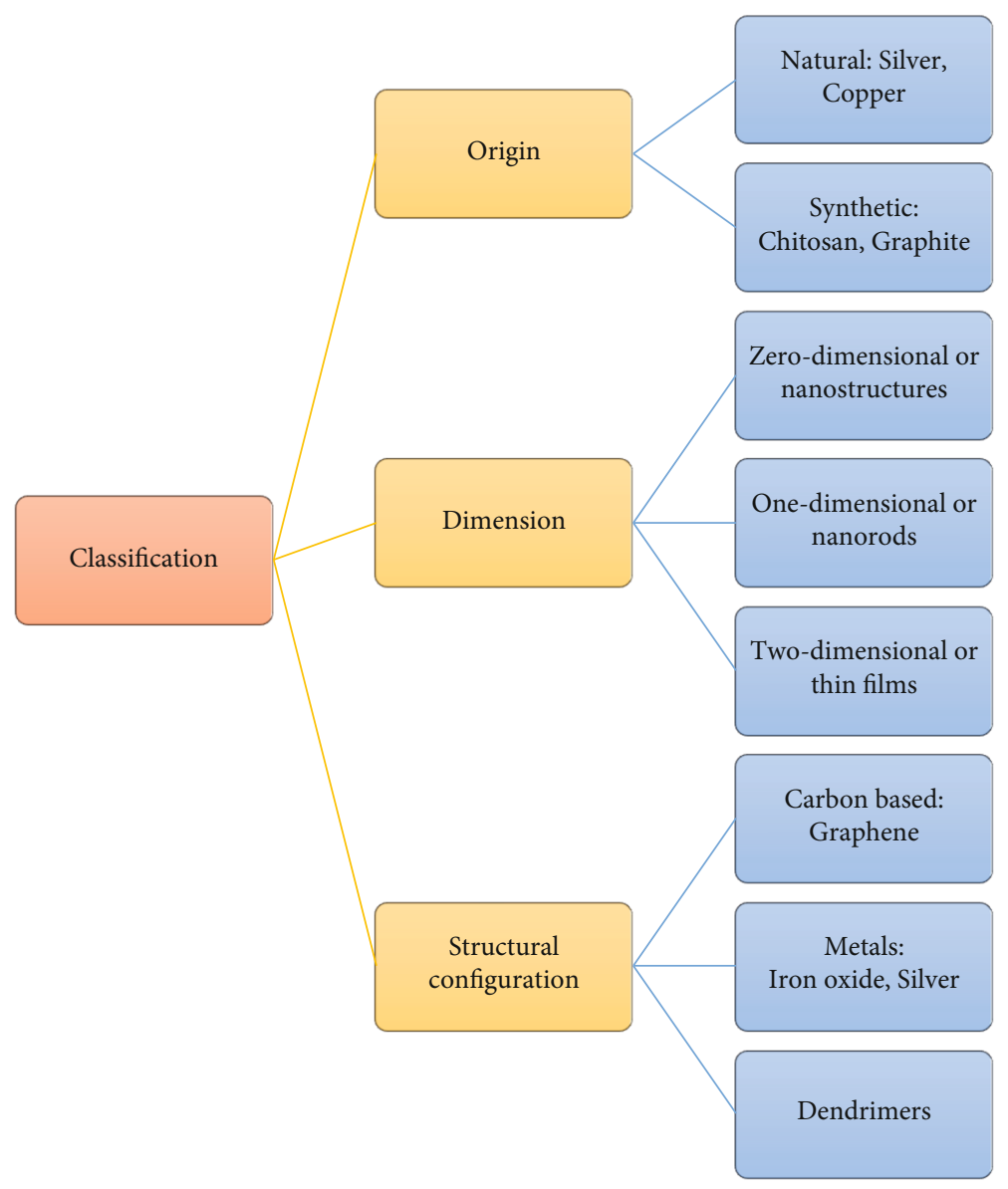

FIGURE 1: Classification of nanoparticles.

nanobiotechnological uses and its production were only examined broadly, not concerning dentistry. As a result, this article is aimed at presenting a literature review on the potential therapeutic application and antimicrobial properties of silver nanoparticles in dentistry, particularly in endodontics.

\section{Materials and Methods}

The relevant MESH terms like antimicrobial, endodontics, silver nanoparticles, and root canal were used to perform an electronic search for literature on the Google Scholar, PubMed, EMBASE, and Web of Science databases. The electronic literature search was conducted on July $5^{\text {th }}, 2021$. The keywords used were antimicrobial properties, mechanism of action, and current applications of silver nanoparticles in dentistry. The search was limited to articles that were published in the English language. There were no deadlines set for publication. In adjunct, supplementary documents on the concerns that had been neglected were identified by scanning the reference lists of each paper presenting data.

The data extracted depends on the antibacterial properties of Ag NPs. The current review focuses on silver NPs employed as antimicrobials in root canal infections and their uses in different fields of dentistry. The following inclusion criteria were used to refine further the search: root canal infections, general antibacterial mechanisms of Ag NPs, the uses of Ag NPs in dentistry, and the antimicrobial effect of Ag NPs in endodontics.

\section{Results and Discussion}

Two researchers (A.H.A. and M.I.K.) performed the search and extraction of required data from the papers included in the current analysis after reading the entire texts. About 185 articles were thought relevant to the reported investigations out of 6420 electronic search results. Only the publications that were required were received after all abstracts were assessed for relevance. After a final electronic and manual search, roughly 47 research publications were helpful in this study.

3.1. Synthesis of Ag NPs. The synthesis of Ag NPs is of enormous concern to investigators because of their wide range of uses. The Ag NPs were first produced by reducing $\mathrm{Ag} \mathrm{NO}_{3}$ (silver nitrate) $0.500 \mathrm{~mol} / \mathrm{L}$ with maltose $1.000 \mathrm{~mol} / \mathrm{L}$ and then stabilizing them with 1.0 g gelatin [29]. Physical, chemical, and biological approaches are used to make Ag NPs [30]. There are two types of methods to produce Ag NPs: (1) bottom-up method and (2) top-down method as shown in Figure 2. In the bottom-up method, the production of Ag NPs is done by self-gathering of atoms to fresh nuclei that evolves into a particle, which can be formed by biological and chemical processes [31]. For the synthesis of NPs, the 'bottom-up' method 


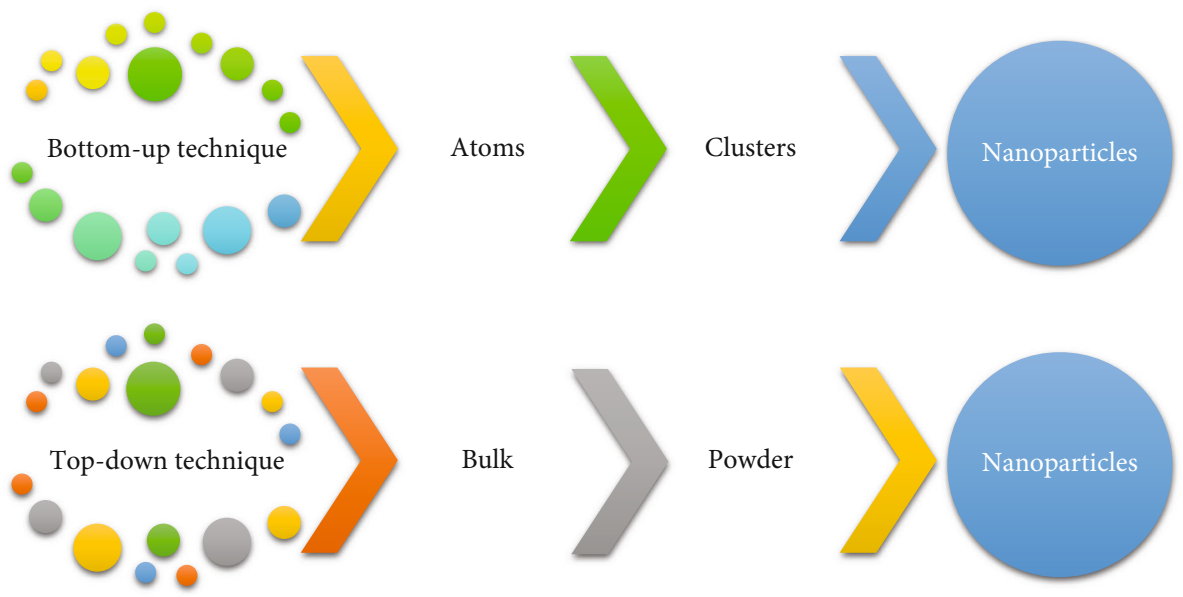

FIgURE 2: Schematic diagram for the bottom-up and top-down approach.

is preferable. It contains a uniform system in which catalysts (enzymes and reducing agents) generate nanomaterials tracked by reaction media, catalytic character, and conditions (such as temperature, solvents, and stabilizers). The chemical reduction approach, for example, is the most widely utilized synthetic route for Ag NPs [7]. In the top-down method, specified ablations, such as thermal decomposition, lithography, mechanical milling, thermal/laser ablation, sputtering, and etching, are used to break down a suitable bulk substance into nanoparticles $[31,32]$. The Ag NPs are generally created in the top-down technique by evaporation/condensation in a tube heater at air compression. The foundation item, held centrally at the furnace within a boat, is boiled away into a carrier gas during this operation. The manufacturing of Ag NPs in a tube furnace has various drawbacks, including the fact that it takes up many places and consumes much power while increasing the ambient heat near the source substance, as well as the fact that it takes several minutes to achieve thermal stability [33, 34]. The synthesis of Ag NPs is explained in Table 1.

The use of plant extracts for Ag NP synthesis has piqued attention because of its environmental friendliness, speed, nonpathogenic, and cost-effectiveness. The application of biomolecules such as alkaloids, proteins, amino acids, enzymes, saponins, carbohydrates, tannins, vitamins, phenolics, enzymes, and terpenoids in the production of Ag NPs has earlier been founded in medicinal plants extracts. It is environmentally friendly, but it includes chemically complex structural elements [35-39].

3.2. Antimicrobial Properties of Ag NPs. The Ag NPs were reported to have a broad antibiotic action on Gram-positive and Gram-negative microorganisms and drug-resistant pathogens. The release of silver ions mainly causes the Ag NPs' antibacterial effect. When the fine Ag NPs $(<10 \mathrm{~nm}$ particle size) are used for antibacterial action, the release of silver is superior to when bigger Ag NPs are employed [40]. The silver ions attach to electron donor assemblies in organic components comprising nitrogen, causing holes in the bacterial membrane, the release of cell contents, and bacterial death [10]. Presently, the silver-based compounds are known to be hazardous to microorganisms. As a result, numerous medici- nal systems that discharge silver ions to achieve antibacterial activity have been developed. Boosting the relative contact area by reducing the size of silver particles, i.e., NPs, is an efficient technique of increasing their efficacy $[41,42]$.

The peptidoglycan bacterial cell wall is destroyed, and the cell membrane is lysed by silver ions. They adhere to DNA bases, causing DNA condensation. As a result, the bacterial cell loses its capacity to divide, stopping the binary fission of bacterial growth. They also solubilize ribosomes, preventing protein synthesis and causing plasma membrane breakdown [30]. The Ag NPs have germicidal properties against Gram-negative bacteria, causing depths to form in their cell walls [43]. Silver interacts with protein DNA of sulfhydryl groups, changing hydrogen bonding, cell growth, respiratory activities, DNA undoing, and cell wall formation [44]. Another way is that when silver NPs come into contact with bacteria, they produce free radicals, which break the cell membrane and render it porous, finally preceding cell mortality [45]. The process of antimicrobial action of Ag NPs is shown in Figure 3 and Table 2.

3.3. Ag NP Uses in Restorative Dentistry. Restoration failure is thought to be caused by restorative materials and mouth microorganisms in dentistry. Antibacterial agents should be used to achieve long-lasting restorations. The nanocomposites and inorganic nanoparticles are applied as effective antimicrobial agents [46]. Secondary caries is the significant cause of dental restorative failure. Several efforts have been undertaken to extend the lifespan of dental restorations by integrating antimicrobial bioactive substances. The gradual discharge of several depleted molecular weight antibacterial agents such as zinc ions, silver ions, chlorhexidine, antibiotics, and iodine was studied [47]. Evidence suggests that microleakage on restoration edges allows oral bacteria to colonize, leading to secondary decay. This results in the failure of restoration and the requirement for replacement or restoration. Antimicrobial agents, such as Ag NPs, can solve the problem by including them into adhesive systems and composite resins [40]. The antibacterial activities of restorative materials containing Ag NPs can minimize the incidence of recurrent decay beneath composite resins due to microleakage. Because of the high preventive action of 
TABLE 1: Demonstration of the different approaches in Ag NP synthesis.

\begin{tabular}{lcccc}
\hline Physical & Chemical & Biological & Top-down & Bottom-up \\
\hline & & & & $\begin{array}{c}\text { Electrochemical precipitation } \\
\text { Vapor deposition } \\
\text { Molecular condensation } \\
\end{array}$ \\
& & & Sechanical milling & Sol-gel process \\
Bal milling & & & Chemical etching & Spray pyrolysis \\
Thermal & Sol-gel processing & Bacteria & Laser ablation & Laser pyrolysis \\
evaporation & Solution-based synthesis & Fungi & Sputtering & Aerosol pyrolysis \\
Lithography & Plant extract (Salvadora persica) & lithography & Green synthesis: bacteria plants \\
Vapor phase & & & Thermal & (gymnosperms to angiosperms) \\
& & & decomposition & Fungus algae \\
& & & & Yeasts \\
& & & & Actinomycetes \\
& & & &
\end{tabular}

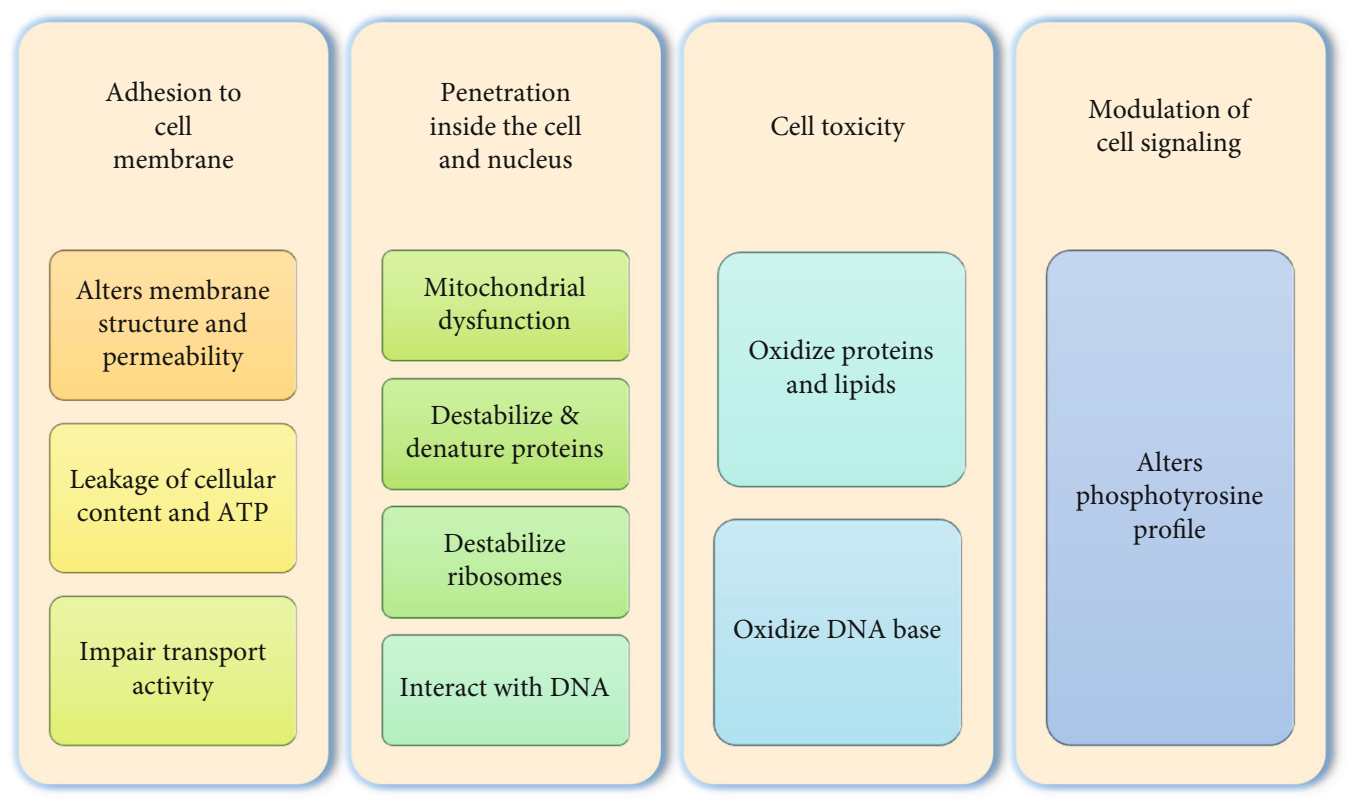

Figure 3: The process of antimicrobial activity of Ag NPs.

TABLE 2: The antimicrobial action of Ag NPs.

\begin{tabular}{|c|c|c|}
\hline Antibacterial action & Antiviral action & Antifungal action \\
\hline $\begin{array}{l}\text { (i) Effective against Gram-positive and } \\
\text { Gram-negative bacteria } \\
\text { (ii) Minimum inhibitory concentration (MIC) } \\
\text { of Ag NPs is in approximately } 0.003 \mathrm{mg} / \mathrm{mL} \\
\text { for Fusobacterium nucleatum } \\
\text { (iii) } 0.04 \mathrm{mg} / \mathrm{mL} \text { for Streptococcus mutans and } \\
0.5 \mathrm{mg} / \mathrm{mL} \text { for Actinomyces oris } \\
\text { (iv) Concentration of } 50-60 \mu \mathrm{gm}^{-3} \text { of Ag NPs } \\
\text { causes } 100 \% \text { prevention of bacterial growth } \\
\text { Escherichia coli } \\
\text { (v) Ag NPs in the range of } 1-10 \text { nm with direct } \\
\text { contact with cell membrane surface change the } \\
\text { permeability and causes cell damage }\end{array}$ & $\begin{array}{l}\text { (i) Effective against Candida } \\
\text { albicans, Fusarium oxysporum } \\
\text { (ii) Attach with the superficial } \\
\text { proteins of viruses inhibiting their } \\
\text { binding and replication }\end{array}$ & $\begin{array}{l}\text { (i) Effective against arenavirus, HIV, murine } \\
\text { norovirus, hepatitis B virus } \\
\text { (ii) Ag NP action against Candida albicans } \\
\text { could be destruction of cell membrane } \\
\text { preventing the growth of cell } \\
\text { (iii) Concentration of } 1 \mu \mathrm{g} / \mathrm{mL} \text { of Ag NPs } \\
\text { included in resins have shown strong antifungal } \\
\text { action without any cytotoxicity }\end{array}$ \\
\hline
\end{tabular}


TABLE 3: Description of the incorporation of Ag NPs into different restorative materials used in dentistry.

\begin{tabular}{ll}
\hline $\begin{array}{l}\text { Type of restorative } \\
\text { material }\end{array}$ & Characteristics \\
\hline & (i) As filler particles, Ag NPs have been integrated into composite resins and adhesive systems \\
(ii) To boost Ag salt solubility in resin solutions, the most frequent way is to add a monomer, commonly \\
2-(tertbutylamino) ethyl methacrylate \\
(iii) Improves the antimicrobial properties of composite material \\
(iv) The mechanical properties of many adhesive systems utilized with such composites are likewise \\
influenced by Ag+
\end{tabular}

TABLe 4: Description of different materials with Ag NPs used in endodontics.

Type of material used in endodontics

\begin{tabular}{|c|c|}
\hline Root canal irrigant & $\begin{array}{l}\text { (i) An Ag NP-based solution for irrigation proved equally effective as sodium hypochlorite in the } \\
\text { removal of Staphylococcus aureus and Enterococcus faecalis } \\
\text { (ii) In comparison to sodium hypochlorite, a low concentration of Ag NPs demonstrated higher } \\
\text { biocompatibility } \\
\text { (iii) In comparison to sodium hypochlorite and chlorhexidine solutions, silver-based root canal } \\
\text { irrigant successfully continued their antibacterial activity }\end{array}$ \\
\hline Intracanal medicament & $\begin{array}{l}\text { (i) Calcium hydroxide in comparison to the } 0.01 \text { percent Ag NP gel and calcium hydroxide } \\
\text { groups, biofilms treated with } 0.02 \text { percent Ag NP gel as a medicament for } 7 \text { days considerably } \\
\text { eliminated the formation with the least amount of residual functional E. faecalis cells } \\
\text { (ii) Mineral trioxide when compared to unmodified MTA, the MTA containing } 1 \% \text { ag NPs have a } \\
\text { stronger antibacterial activity against bacteria and fungi. Mineral trioxide aggregate with Ag NPs is } \\
\text { biocompatible and does not cause inflammation }\end{array}$ \\
\hline
\end{tabular}

(i) Gutta-percha coated with Ag NPs have antibacterial and antifungal characteristic which made them as effective as in preventing bacterial leakage

Gutta-percha form of gutta-percha in endodontic treatments might be more effective

(iii) Substantial antimicrobial effect against Staphylococcus aureus, Candida albicans, E faecalis, and E coli

Root canal sealer

(i) A new endodontic sealer with Ag NPs has potent antibiofilm abilities

(ii) Do not cooperate the sealing and physical assets of a sealer

$[48,70$, bacteria causing caries, restorative adhesives containing Ag NPs may interfere with biofilm growth [48]. Cheng et al. [49] investigated the mechanical characteristics and biofilm formation of Ag NPs inserted into composite resin in a study published in 2013. According to this study, the mechanical characteristics of composites were not affected when Ag NPs were added at concentrations of 0.028 and 0.042 . When the Ag NP concentration was 0.042, however, Streptococcus mutans colony-forming units were reduced by $75 \%$. The types of material used in restorative dentistry with incorporation Ag NPs were explained in Table 3.

3.4. Ag NPs Used in Endodontics. Antibiotic resistance and recurrent infections, which can lead to treatment failure, are critical issues in the field of endodontics [6]. For a successful root canal therapy, complete inhibition and eradication of microorganisms from the root canal system is critical. Subsequently, after rigorous root canal disinfection, instrumentation, and obturation, microorganisms can still be found in the root canal [50]. According to research on unsuccessful endodontic therapy, apical periodontitis in root canal-treated teeth is frequently composed of several types of microbial infections. Many samples have been found to contain Enterococcus faecalis $[51,52]$. While E. faecalis infects the dentinal tubules and cementum, it is resistant to most root canal disinfectants and can persist for extended periods inside the dentinal tubules, even in diminished nutrient environments [53]. When compared to 2\% chlorhexidine, Ag NPs had the maximum zone of inhibition $(19.55 \mathrm{~mm})$ and the lowest zone of inhibition $(10.32 \mathrm{~mm})$ against E. Faecalis, indicating that it might be employed as an alternate antibacterial for endodontic disinfection [54]. The discharge of Ag+ ions, which provide an 
TABle 5: Demonstration of material combinations with Ag NPs used in dentistry.

\begin{tabular}{lll}
\hline $\begin{array}{l}\text { Department of } \\
\text { dentistry }\end{array}$ & Biomaterials & References \\
\hline & $\begin{array}{l}\text { (i) Acrylic resin-the Ag NPs can be mixed into acrylic resin to stop the development of } \\
\text { microorganisms like Streptococcus aureus, E. coli, and Staphylococcus mutans }\end{array}$ & $\begin{array}{l}\text { (ii) Porcelain-the latent compressive stress induced by a differential thermal expansion and ion } \\
\text { exchange reaction of silver nanoparticles in porcelain is responsible for its reinforced mechanical }\end{array}$ \\
Prosthodontics & [78, 79] \\
& qualities, including as hardness and fracture toughness
\end{tabular}

(i) Guided tissue regeneration (GTR) - the GTR membrane with Ag NPs decreased the bacterial adhesion and permeation, treating intrabony defects and increase clinical outcomes (ii) Periodontal dressings-periodontal dressings A (25 percent $v / v)$ and B (50 percent $v / v)$ of Ag NP Periodontics concentration were utilized to determine the optimal Ag NP dosages for postsurgery healing of periodontal wounds

(iii) Capping agent-sodium alginate capped Ag NPs encourage the suppression of Gram-negative bacteria, which are the most common cause of periodontal diseases

(i) Adhesives-when compared to conventional adhesives, Ag NPs significantly reduced adhesion of Orthodontics streptococci to orthodontic adhesives while maintaining shear bond strength

(ii) Cements-cements with Ag NPs could be used to avoid white spot lesions in orthodontic treatments

(i) Modification of implant surfaces with Ag NPs utilizing numerous doping approaches is presently a hot topic, related to the safety and effective bactericidal capabilities of Ag NPs

Dental implants

(ii) Dental implants made of titanium infused with Ag NPs can improve bone mineral thickness, bone growth, and trabecular shape while causing no damage to the tissues surrounding the implants

(i) Cements-the antibacterial activity is mediated by the discharge of Ag ions, who induces oxidative breakdown in the cement substance, preventing the formation of oral biofilms and suppressing tooth

Pedodontics caries



(ii) Resins-Ag NPs was added into a resin matrix, which is employed in chitosan polymer-based restorations of deciduous and permanent dentitions

(i) Silver ions can precipitate and penetrate in carious lesions, causing enamel hardness

Preventive dentistry (ii) Dental surgeons employ varnish like silver nanofluoride and silver diamine fluoride in the clinical practice to remineralize incipient lesions

(i) Anticancer effect-early detection of malignancies and the use of a drug delivery method to a Oral and maxillofacial cancer-affected spot can be advantageous because it reduces the patient's anxiety

surgery (ii) The green route method for Ag NPs was discovered to have an immediate suppressive anticancer effects

electrodynamic affinity to sulphur proteins, causes adhesion to bacterial cell membrane and rupture. Silver ions taken in the cell can cause malfunction of respiratory enzymes, causing responsive oxygen groups to form and adenosine triphosphate production to be disrupted. Direct denaturation of DNA and ribosomes can also be caused by silver ions [55]. Since it successfully dissolved E. faecalis biofilm and removed the bacteria from infected dentinal tubules, the Ag NP solution is an effective root canal irrigant [30]. The different uses of Ag NPs used in endodontics are explained in Table 4.

3.5. Ag NPs Used as Biomaterials in Dentistry. The application of Ag in dentistry dates back to the 19th century and exhibits various uses, owing to silver ions' antibacterial properties. [56]. Meanwhile, the emergence of nanotechnology in the twentyfirst century gave rise to a new viewpoint on using silver in dentistry in the type of Ag NPs, which exhibit antibacterial properties owing to the slow discharge of silver ions [57]. The Ag NP research has risen in popularity in the modern era. The primary factor is that Ag NPs may modify the growth processes and nucleation with various synthetic chemicals.
Secondly, molecular covering agents like chemical groups and proteins can be used to precisely form Ag NPs. Thirdly, Ag NPs have a powerful antimicrobial impact that enhances clinical treatment results [58]. The primary goal of incorporating Ag NPs into dental products is to prevent or reduce the development of biofilms and the proliferation of microbes [59]. Therefore, the discovery of broad-spectrum antimicrobials that can be successfully included in dental biomaterials is critical. As a result, uniform silver nanoparticles with regulated size, shape, and action can be considered multipurpose parts in various dental biomaterials [48]. They have a superior antibacterial effect without altering the material's mechanical qualities due to their higher volume to surface area ratio and lesser particle dimension. The Ag NPs have unique features that make them ideal fillers for various biomaterials, where they play a critical role in improving qualities [40]. The uses of Ag NPs in different biomaterials are explained in Table 5.

3.6. Toxicity of Silver Nanoparticles. The biosafety and biocompatibility aspect of using Ag NPs in managing the individual illness, healing intervention, and directed medicine distribution 
is the most significant and critical challenge. The growing popularity of Ag NP-based antimicrobials raises concerns about the clinical risks and biosafety they pose to humans [31]. The Ag NPs have a constant set of flexible features that make them suitable for various biomedical and associated applications. The Ag NPs were subjected to several in vivo and in vitro investigations over the years in order to learn more about their harmful effects on live tissues and organisms. Because of their antibacterial properties, Ag NPs remain the most extensively used nanocompound on the market. As the use of Ag NP products grows, so does the risk of negative effects on the environment and human health. The Ag NPs have distinct physiochemical qualities (surface area, size, capacity to aggregate, chemical composition of surface chemistry, and solubility) and biological activities than pure silver. These physiochemical traits result in a greater surface area, which increases toxicity [60]. Recent research has linked Ag NPs of various sizes and shapes to inflammatory, pulmonary inflammation, hepatotoxic, cytotoxic, neurotoxic, and genotoxic effects [61]. The dose limit for the usage of Ag NP in dentistry is considered to be less than $18 \mathrm{mg} / \mathrm{kg}$ of body weight, whereas greater than $20 \mathrm{mg} / \mathrm{kg}$ body weight is toxic [62]. The toxic effects of Ag NPs were shown to be precisely connected to the interaction of free Ag ions discharged in the medium [58]. Orally administered silver has been found in the range of $0.4-18 \mathrm{mg}$ particles/ $\mathrm{kg}$ of body weight/day and 18 percent in animals and humans, respectively. Silver appears to be distributed throughout all the organs examined, with the highest concentrations seen in the intestine and stomach. Silver causes argyria, a blue-grey staining of the skin [63]. The Ag NPs can easily disrupt human organ's biological molecules and cells due to their nanosize. According to some laboratory research, Ag NPs can cause oxidative emphasis in human cells and disrupt the function of mitochondria [64]. When silver and Ag NPs were given orally, the nanoparticles were shown to be less absorbed, with increased fecal excretion and lower amounts in organs [65]. Nanoparticles have a more complicated absorption mechanism than smaller molecules. Orally administered nanoparticles are absorbed primarily by macrophages and lymphatic uptake, while subcutaneous, intramuscular, and inhaled nanoparticles are absorbed primarily through paracellular transport, transcytosis, and $\mathrm{M}$ cell uptake in the GI tract [66]. Ag NPs were shown to pass the blood-brain barrier in rats, causing neural necrosis and deterioration due to long-term buildup in the brain [67]. Following a 28-day repeated oral exposure to $14 \mathrm{~nm}$ PVP-coated Ag NPs or silver acetate in rats, researchers found low silver excretion in urine $(0.1 \%$ of $24 \mathrm{~h}$ intake for both groups) but high excretion of silver in feces (63 and 49\% of daily dose for Ag NPs and silver acetate groups, respectively, and high excretion of silver in feces (63 and $49 \%$ of daily dose for Ag NPs and silver acetate [66]. The biological half-life of silver in humans (liver) ranges from several to 50 days [68]. The toxic effects of Ag NPs on the human body are explained in Figure 4.

3.7. Future Implications and Recommendations. Because laboratory conditions do not wholly replicate oral situations, one of the most crucial experiments to conduct is applying bench data to in vivo research. Another element to be exam-

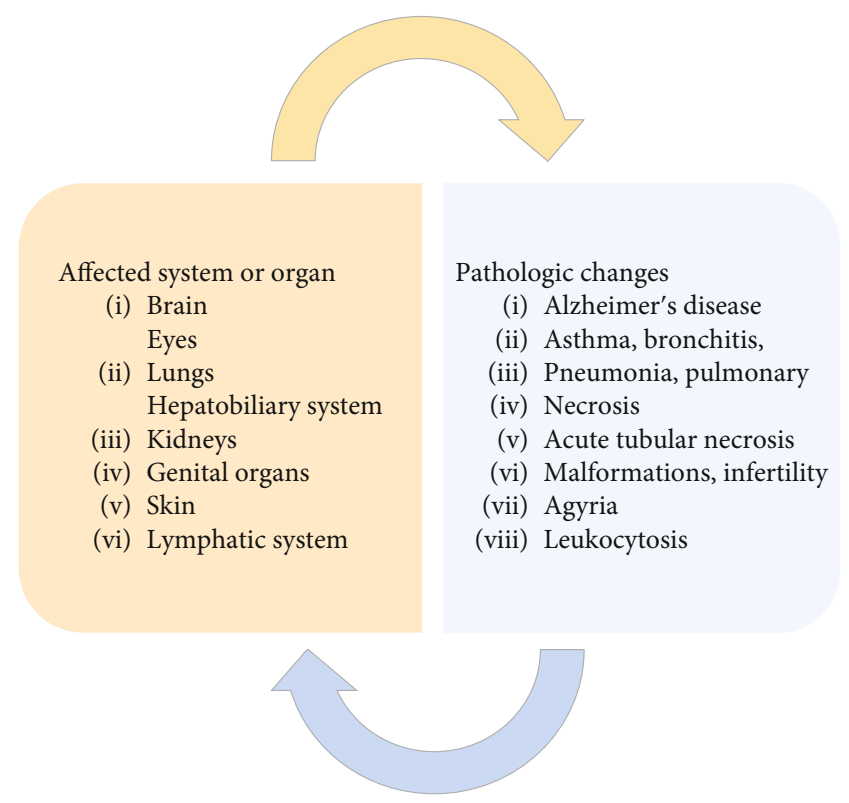

Figure 4: The toxic effects of Ag NPs.

ined is the long-standing efficiency of Ag NPs related to dental materials, as they should have a long-lasting antibacterial activity [59]. However, there has been a global rise in publications and technical progress on Ag NP in the health field, indicating a rise in investigations on this expertise, which has presently demonstrated the antimicrobial property of Ag NPs in nanocomposites or when combined with biomaterials. For restorative, prosthetic, periodontal, endodontic, orthodontic, and implant treatment, a rising variety of dental materials, including Ag NPs, are being manufactured and are shown in Figure 5. Human cells were found to be cytotoxic by silver nanoparticles in several laboratory investigations. However, the statistical significance of silver nanoparticles' possible toxicity is uncertain. Because clinical data is currently minimal, more research is needed [48]. When used at concentrations low in cytotoxicity to the patient's cells, the Ag NPs appear as antimicrobial means for preventing pathogens, inflammation of tissue, caries' activity, and bone loss [57]. Since Ag NPs are frequently related to dental biomaterials, the breadth of technological areas is still more apparent, such as the discovery of the Ag-PMMA nanocomposite film established on Aristo lochia bracteolate with preventive action on E. coli, growth of Bacillus cereus and E Coli in aqueous liquids [69]. There are numerous viable products and therapeutic applications like wound coverings, which have already been established for Ag NPs, while many other potential applications are being thoroughly researched. Because of the anti-inflammatory, antiviral, antibacterial, and antifungal capabilities, the Ag NPs have much potential, and recent research has discovered new osteoinductive assets as well. Though, the processes and biological relations that underpin these characteristics are still unknown [67]. Another innovation is putting Ag NPs on the surface of a tooth implant to provide it antibacterial qualities. This is an example of surfacing and coated technology as well as the pharmaceutical technological arena. Some patents also cover preventative dentistry, such as antibacterial, antifungal, and local 


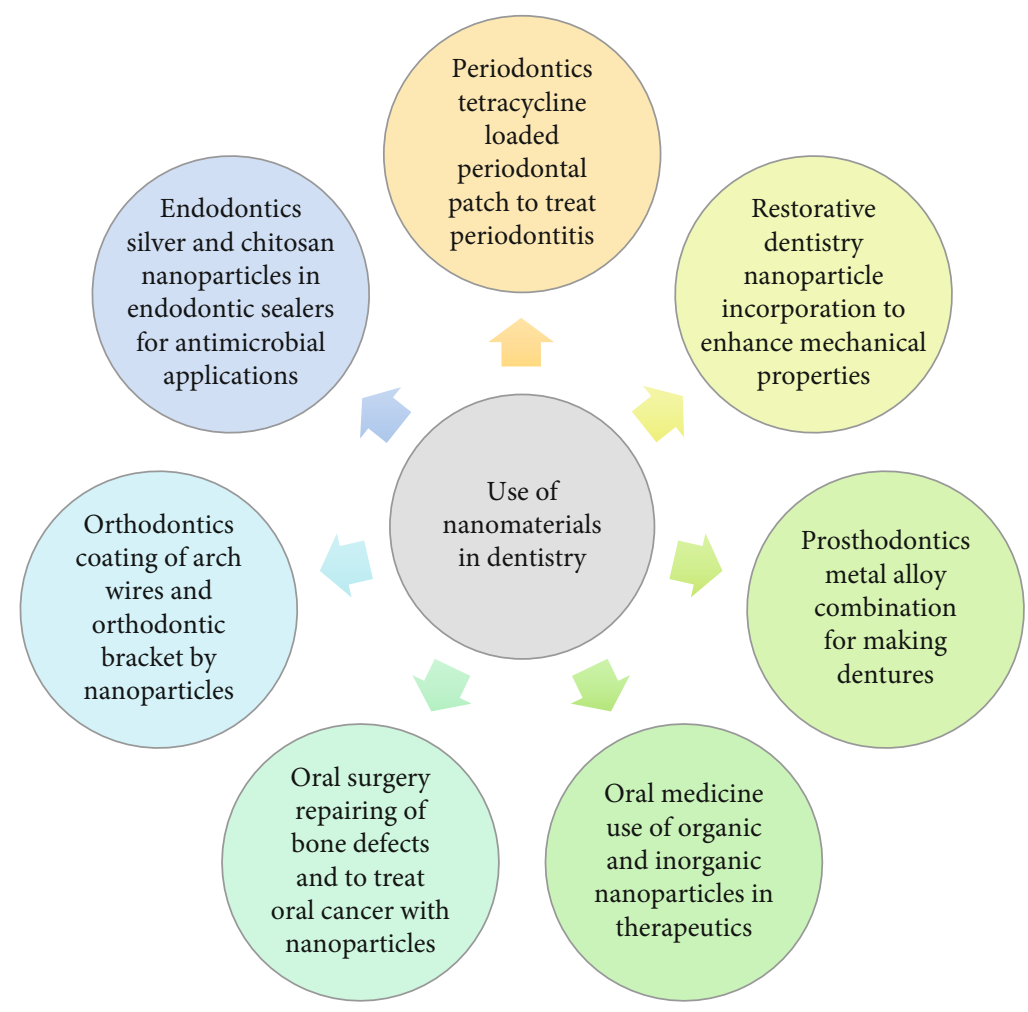

FIgURE 5: Uses of nanomaterials in dentistry.

anesthetic oral and throat care medicines that can be administered daily. They also have organoleptic qualities essential for dental treatments such as gum strengthening and gingival bleeding reduction [57]. Clinical trials are required before Ag NPs or Ag NP-based formulations can treat human therapeutic interventions or disease management. There are, nevertheless, some significant impediments. In this regard, we believe that further research should occur in three steps before Ag NPs can be used in therapeutic interferences, clinical trials, or drug release therapies. However, there are issues and controversies about the safe application of Ag NPs in the treatment of diseases and healthcare, and there are some benefits to using them. According to research so far, the Ag NPs can be modified to boost their antibacterial stability, usefulness, biosafety, specificity, and biocompatibility for larger therapeutic assistance and condensed possible toxicity.

\section{Conclusion}

The Ag NPs, unlike other biomaterials used in dentistry, have unique biological features and could be used in endodontics, restorative dentistry, periodontology, prosthetic dentistry, implantology, and oral malignancies, because of their antiviral, antibacterial, and antifungal properties. The Ag NPs are among the most outstanding nanomaterials used in industrial and commercial applications. Antimicrobial, technological, and biomedical products have all made substantial use of it. This narrative review provides a broad summary of Ag NPs, including synthesis, antimicrobial properties, use in restorative dentistry, use in endodontics, Ag NPs in dental biomaterials, and potential toxicity concerns.

\section{Data Availability}

All types of data used to support these review findings have been included in this article.

\section{Conflicts of Interest}

The authors declare that they have no conflicts of interest.

\section{References}

[1] S. Gurunathan, J. W. Han, D. N. Kwon, and J. H. Kim, "Enhanced antibacterial and anti-biofilm activities of silver nanoparticles against Gram-negative and Gram-positive bacteria," Nanoscale Research Letters, vol. 9, no. 1, pp. 1-17, 2014.

[2] A. Byström, R. Claesson, and G. Sundqvist, "The antibacterial effect of camphorated paramonochlorophenol, camphorated phenol and calcium hydroxide in the treatment of infected root canals," Dental Traumatology, vol. 1, no. 5, pp. 170-175, 1985.

[3] C. Rocha, M. A. Rossi, M. R. Leonardo, L. B. Rocha, P. NelsonFilho, and L. A. B. Silva, "Biofilm on the apical region of roots in primary teeth with vital and necrotic pulps with or without radiographically evident apical pathosis," International Endodontic Journal, vol. 41, no. 8, pp. 664-669, 2008.

[4] D. Ricucci, S. Loghin, and J. F. Siqueira Jr., "Exuberant biofilm infection in a lateral canal as the cause of short-term endodontic treatment failure: report of a case," Journal of Endodontics, vol. 39, no. 5, pp. 712-718, 2013.

[5] R. A. Fernandes, D. R. Monteiro, L. S. Arias, G. L. Fernandes, A. C. B. Delbem, and D. B. Barbosa, "Biofilm formation by Candida albicans and Streptococcus mutans in the presence 
of farnesol: a quantitative evaluation," Biofouling, vol. 32, no. 3 , pp. 329-338, 2016.

[6] P. Nair, S. Henry, V. Cano, and J. Vera, "Microbial status of apical root canal system of human mandibular first molars with primary apical periodontitis after "one-visit" endodontic treatment," Oral Surgery, Oral Medicine, Oral Pathology, Oral Radiology, and Endodontology, vol. 99, no. 2, pp. 231-252, 2005.

[7] S. L. Pal, U. Jana, P. K. Manna, G. P. Mohanta, and R. Manavalan, "Nanoparticle: an overview of preparation and characterization," Journal of Applied Pharmaceutical Science, vol. 1, no. 6, pp. 228-234, 2011.

[8] S. Ahmed, M. Ahmad, B. L. Swami, and S. Ikram, "A review on plants extract mediated synthesis of silver nanoparticles for antimicrobial applications: a green expertise," Journal of Advanced Research, vol. 7, no. 1, pp. 17-28, 2016.

[9] J. Spadaro, T. J. Berger, S. D. Barranco, S. E. Chapin, and R. O. Becker, "Antibacterial effects of silver electrodes with weak direct current," Antimicrobial Agents and Chemotherapy, vol. 6, no. 5, pp. 637-642, 1974.

[10] C. Damm, H. Münstedt, and A. Rösch, "The antimicrobial efficacy of polyamide 6/silver-nano- and microcomposites," Materials Chemistry and Physics, vol. 108, no. 1, pp. 61-66, 2008.

[11] A. Shrestha and A. Kishen, "Antibacterial nanoparticles in endodontics: a review," Journal of Endodontics, vol. 42, no. 10, pp. 1417-1426, 2016.

[12] N. Takahashi, "Oral microbiome metabolism: from "who are they?" to "what are they doing?", Journal of Dental Research, vol. 94, no. 12, pp. 1628-1637, 2015.

[13] T.-O. Peulen and K. J. Wilkinson, "Diffusion of nanoparticles in a biofilm," Environmental Science \& Technology, vol. 45, no. 8, pp. 3367-3373, 2011.

[14] N. I. Abu-Lail and T. A. Camesano, "Role of lipopolysaccharides in the adhesion, retention, and transport of Escherichia coli JM109," Environmental Science \& Technology, vol. 37, no. 10, pp. 2173-2183, 2003.

[15] M. Rai, A. P. Ingle, A. K. Gade, M. C. T. Duarte, and N. Duran, "Three Phoma spp. synthesised novel silver nanoparticles that possess excellent antimicrobial efficacy," IET Nanobiotechnology, vol. 9, no. 5, pp. 280-287, 2015.

[16] M. Rai, K. Kon, A. Ingle, N. Duran, S. Galdiero, and M. Galdiero, "Broad-spectrum bioactivities of silver nanoparticles: the emerging trends and future prospects," Applied Microbiology and Biotechnology, vol. 98, no. 5, pp. 1951-1961, 2014.

[17] M. Rai, S. Birla, A. P. Ingle et al., "Nanosilver: an inorganic nanoparticle with myriad potential applications," Nanotechnology Reviews, vol. 3, no. 3, pp. 281-309, 2014.

[18] M. Rai, A. P. Ingle, A. Gade, and N. Duran, "Synthesis of silver nanoparticles by Phoma gardeniae and in vitro evaluation of their efficacy against human disease-causing bacteria and fungi," IET Nanobiotechnology, vol. 9, no. 2, pp. 71-75, 2015.

[19] Y. Liu, Z. Zheng, J. N. Zara et al., "The antimicrobial and osteoinductive properties of silver nanoparticle/poly (dl-lactic-co-glycolic acid)-coated stainless steel," Biomaterials, vol. 33, no. 34, pp. 8745-8756, 2012.

[20] R. E. Nuñez-Anita, L. S. Acosta-Torres, J. Vilar-Pineda, J. C. Martínez-Espinosa, J. de la Fuente-Hernández, and V. M. Castaño, "Toxicology of antimicrobial nanoparticles for prosthetic devices," International Journal of Nanomedicine, vol. 9, p. 3999, 2014.

[21] B. Tian, W. Chen, Y. Dong et al., "Silver nanoparticle-loaded hydroxyapatite coating: structure, antibacterial properties, and capacity for osteogenic induction In Vitro," RSC Advances, vol. 6, no. 11, pp. 8549-8562, 2016.

[22] American Association of Endodontists, Glossary of endodontic terms, American Association of Endodontists, 2003.

[23] A. Shrestha and A. Kishen, "Antibiofilm efficacy of photosensitizer-functionalized bioactive nanoparticles on multispecies biofilm," Journal of Endodontics, vol. 40, no. 10, pp. 1604-1610, 2014.

[24] T. V. Slenters, I. Hauser-Gerspach, A. U. Daniels, and K. M. Fromm, "Silver coordination compounds as light-stable, nano-structured and anti-bacterial coatings for dental implant and restorative materials," Journal of Materials Chemistry, vol. 18, no. 44, pp. 5359-5362, 2008.

[25] S. L. Percival, P. Bowler, and D. Russell, "Bacterial resistance to silver in wound care," Journal of Hospital Infection, vol. 60, no. 1, pp. 1-7, 2005.

[26] J. F. B. Bruniera, Y. T. C. Silva-Sousa, M. G. Lara, A. PitondoSilva, A. M. Marcaccini, and C. E. S. Miranda, "Development of intracanal formulation containing silver nanoparticles," Brazilian Dental Journal, vol. 25, no. 4, pp. 302-306, 2014

[27] N. Jonaidi-Jafari, M. Izadi, and P. Javidi, “The effects of silver nanoparticles on antimicrobial activity of ProRoot mineral trioxide aggregate (MTA) and calcium enriched mixture (CEM)," Journal of Clinical and Experimental Dentistry, vol. 8, no. 1, article e22, 2015.

[28] M. S. Mendes, L. D. Resende, C. A. Pinto, D. P. Raldi, F. G. Cardoso, and S. M. Habitante, "Radiopacity of mineral trioxide aggregate with and without inclusion of silver nanoparticles," The Journal of Contemporary Dental Practice, vol. 18, no. 6, pp. 448-451, 2017.

[29] J. F. B. Bruniera, L. Gabriel-Silva, R. S. Goulart et al., "Green synthesis, characterization and antimicrobial evaluation of silver nanoparticles for an intracanal dressing," Brazilian Dental Journal, vol. 31, no. 5, pp. 485-492, 2020.

[30] S. Mitthra, L. Saatwika, B. Anuradha, and A. Subbiya, "Application of silver nanoparticles in conservative and endodontics," Indian Journal of Public Health, vol. 10, no. 8, p. 1634, 2019.

[31] M. A. Barkat, Harshita, S. Beg et al., "Current progress in synthesis, characterization and applications of silver nanoparticles: precepts and prospects," Recent Patents on AntiInfective Drug Discovery, vol. 13, no. 1, pp. 53-69, 2018.

[32] M. Gomathi, A. Prakasam, R. Chandrasekaran, G. Gurusubramaniam, K. Revathi, and S. Rajeshkumar, "Assessment of silver nanoparticle from Cocos nucifera (coconut) shell on dengue vector toxicity, detoxifying enzymatic activity and predatory response of aquatic organism," Journal of Cluster Science, vol. 30, no. 6, pp. 1525-1532, 2019.

[33] M. E. Samberg, S. J. Oldenburg, and N. A. Monteiro-Riviere, "Evaluation of silver nanoparticle toxicity in skin in vivo and keratinocytes in vitro," Environmental Health Perspectives, vol. 118, no. 3, pp. 407-413, 2010.

[34] M.-C. Daniel and D. Astruc, "Gold nanoparticles: assembly, supramolecular chemistry, quantum-size-related properties, and applications toward biology, catalysis, and nanotechnology," Chemical Reviews, vol. 104, no. 1, pp. 293-346, 2004.

[35] N. Kulkarni and U. Muddapur, "Biosynthesis of metal nanoparticles: a review," Journal of Nanotechnology, vol. 2014, Article ID 510246, 8 pages, 2014.

[36] H. Agarwal, S. Menon, S. Rajeshkumar, and S. V. Kumar, "Green synthesis of silver nanoparticle using Kalanchoe 
pinnata leaf extract and its antibacterial effect against grampositive and gram-negative species," Research Journal of Pharmacy and Technology, vol. 11, no. 9, pp. 3964-3968, 2018.

[37] P. Karthiga, S. Rajeshkumar, and G. Annadurai, "Mechanism of larvicidal activity of antimicrobial silver nanoparticles synthesized using Garcinia mangostana bark extract," Journal of Cluster Science, vol. 29, no. 6, pp. 1233-1241, 2018.

[38] S. Rajeshkumar, "Synthesis of silver nanoparticles using fresh bark of Pongamia pinnata and characterization of its antibacterial activity against gram positive and gram negative pathogens," Resource-Efficient Technologies, vol. 2, no. 1, pp. 3035, 2016.

[39] S. Rajeshkumar, C. Malarkodi, M. Vanaja, and G. Annadurai, "Anticancer and enhanced antimicrobial activity of biosynthesizd silver nanoparticles against clinical pathogens," Journal of Molecular Structure, vol. 1116, pp. 165-173, 2016.

[40] R. A. Bapat, T. V. Chaubal, C. P. Joshi et al., "An overview of application of silver nanoparticles for biomaterials in dentistry," Materials Science and Engineering: C, vol. 91, pp. 881-898, 2018.

[41] P. Kaur and R. Luthra, "Silver nanoparticles in dentistry: an emerging trend," SRM Journal of Research in Dental Sciences, vol. 7, no. 3, p. 162, 2016.

[42] S. Rajeshkumar, "Phytochemical constituents of fucoidan (Padina tetrastromatica) and its assisted AgNPs for enhanced antibacterial activity," IET Nanobiotechnology, vol. 11, no. 3, pp. 292-299, 2017.

[43] I. Sondi and B. Salopek-Sondi, "Silver nanoparticles as antimicrobial agent: a case study on _E. coli_as a model for Gramnegative bacteria," Journal of Colloid and Interface Science, vol. 275, no. 1, pp. 177-182, 2004.

[44] A. B. Lansdown, "Silver in health care: antimicrobial effects and safety in use," Biofunctional Textiles and the Skin, vol. 33, pp. 17-34, 2006.

[45] M. Danilczuk, A. Lund, J. Sadlo, H. Yamada, and J. Michalik, "Conduction electron spin resonance of small silver particles," Spectrochimica Acta Part A: Molecular and Biomolecular Spectroscopy, vol. 63, no. 1, pp. 189-191, 2006.

[46] K. Fatemeh, M. Mohammad Javad, and K. Samaneh, “The effect of silver nanoparticles on composite shear bond strength to dentin with different adhesion protocols," Journal of Applied Oral Science, vol. 25, no. 4, pp. 367-373, 2017.

[47] D. Xie, Y. Weng, X. Guo, J. Zhao, R. L. Gregory, and C. Zheng, "Preparation and evaluation of a novel glass-ionomer cement with antibacterial functions," Dental Materials, vol. 27, no. 5, pp. 487-496, 2011.

[48] I. X. Yin, J. Zhang, I. S. Zhao, M. L. Mei, Q. Li, and C. H. Chu, "The antibacterial mechanism of silver nanoparticles and its application in dentistry," International Journal of Nanomedicine, vol. 15, pp. 2555-2562, 2020.

[49] L. Cheng, M. D. Weir, H. H. K. Xu et al., "Effect of amorphous calcium phosphate and silver nanocomposites on dental plaque microcosm biofilms," Journal of Biomedical Materials Research Part B: Applied Biomaterials, vol. 100B, no. 5, pp. 1378-1386, 2012.

[50] J. F. Siqueira, I. N. Rôças, and D. Ricucci, "Biofilms in endodontic infection," Endodontic Topics, vol. 22, no. 1, pp. 3349, 2010.

[51] A. Molander, C. Reit, G. Dahlén, and T. Kvist, "Microbiological status of root-filled teeth with apical periodontitis," International Endodontic Journal, vol. 31, no. 1, pp. 1-7, 1998.
[52] H. Hancock III, A. Sigurdsson, M. Trope, and J. Moiseiwitsch, "Bacteria isolated after unsuccessful endodontic treatment in a North American population," Oral Surgery, Oral Medicine, Oral Pathology, Oral Radiology, and Endodontology, vol. 91, no. 5, pp. 579-586, 2001.

[53] R. S. Halkai, M. N. Hegde, and K. R. Halkai, "Evaluation of Enterococcus faecalis adhesion, penetration, and method to prevent the penetration of Enterococcus faecalis into root cementum: confocal laser scanning microscope and scanning electron microscope analysis," Journal of Conservative Dentistry, vol. 19, no. 6, p. 541, 2016.

[54] K. R. Halkai, J. A. Mudda, V. Shivanna, V. Rathod, and R. Halkai, "Evaluation of antibacterial efficacy of fungalderived silver nanoparticles against Enterococcus faecalis," Contemporary Clinical Dentistry, vol. 9, no. 1, pp. 45-48, 2018.

[55] S. Bhandi, D. Mehta, M. Mashyakhy et al., "Antimicrobial efficacy of silver nanoparticles as root canal Irrigant's: a systematic review," Journal of Clinical Medicine, vol. 10, no. 6, p. 1152, 2021.

[56] J.-Y. Peng, M. Botelho, and J. Matinlinna, "Silver compounds used in dentistry for caries management: a review," Journal of Dentistry, vol. 40, no. 7, pp. 531-541, 2012.

[57] C. C. Fernandez, A. R. Sokolonski, M. S. Fonseca et al., "Applications of silver nanoparticles in dentistry: advances and technological innovation," International Journal of Molecular Sciences, vol. 22, no. 5, p. 2485, 2021.

[58] V. T. Noronha, A. J. Paula, G. Durán et al., "Silver nanoparticles in dentistry," Dental Materials, vol. 33, no. 10, pp. 11101126, 2017.

[59] J. M. Corrêa, M. Mori, H. L. Sanches, A. D. . Cruz, E. Poiate, and I. A. V. P. Poiate, "Silver nanoparticles in dental biomaterials," International Journal of Biomaterials, vol. 2015, 9 pages, 2015.

[60] S. P. Singh, C. S. Bhargava, V. Dubey, A. Mishra, and Y. Singh, "Silver nanoparticles: biomedical applications, toxicity, and safety issues," International Journal of Research in Pharmacy and Pharmaceutical Sciences, vol. 4, no. 2, pp. 1-10, 2017.

[61] L. Z. Flores-López, H. Espinoza-Gómez, and R. Somanathan, "Silver nanoparticles: electron transfer, reactive oxygen species, oxidative stress, beneficial and toxicological effects. Mini review," Journal of Applied Toxicology, vol. 39, no. 1, pp. 1626, 2019.

[62] Z. Ferdous and A. Nemmar, "Health impact of silver nanoparticles: a review of the biodistribution and toxicity following various routes of exposure," International Journal of Molecular Sciences, vol. 21, no. 7, p. 2375, 2020.

[63] N. Hadrup and H. R. Lam, "Oral toxicity of silver ions, silver nanoparticles and colloidal silver - a review," Regulatory Toxicology and Pharmacology, vol. 68, no. 1, pp. 1-7, 2014.

[64] R. Y. Chou, "Volatility persistence and stock valuations: some empirical evidence using GARCH," Journal of Applied Econometrics, vol. 3, no. 4, pp. 279-294, 1988.

[65] M. van der Zande, R. J. Vandebriel, E. van Doren et al., "Distribution, elimination, and toxicity of silver nanoparticles and silver ions in rats after 28-day oral exposure," ACS Nano, vol. 6, no. 8, pp. 7427-7442, 2012.

[66] Z. Lin, N. A. Monteiro-Riviere, and J. E. Riviere, "Pharmacokinetics of metallic nanoparticles," Wiley Interdisciplinary Reviews: Nanomedicine and Nanobiotechnology, vol. 7, no. 2, pp. 189-217, 2015.

[67] M. Murphy, K. Ting, X. Zhang, C. Soo, and Z. Zheng, "Current development of silver nanoparticle preparation, investigation, 
and application in the field of medicine," Journal of Nanomaterials, vol. 2015, Article ID 696918, 12 pages, 2015.

[68] H. G. Seiler, H. Sigel, and A. Sigel, Handbook on Toxicity of Inorganic Compounds, Marcel Dekker, New York, NY (USA), 1988.

[69] M. A. Awad, A. A. Hendi, K. M. O. Ortashi, A. B. Alanazi, B. A. ALZahrani, and D. A. Soliman, "Greener synthesis, characterization, and antimicrobiological effects of helba silver nanoparticle-PMMA nanocomposite," International Journal of Polymer Science, vol. 2019, Article ID 4379507, 7 pages, 2019.

[70] L. Moghadas, T. Narimani, and M. Shahmoradi, “Antimicrobial activity of a new nanobased endodontic irrigation solution: in vitro study," Dental Hypotheses, vol. 3, no. 4, p. 142, 2012.

[71] M. Samiei, S. Davaran, F. Valipour, A. Davari, T. Ghiasian, and F. Lotfipour, "Antibacterial efficacy of silver-crosslinked hydrogel nanocomposite versus sodium hypochlorite and chlorhexidine on Enterococcus faecalis for use in root canal infection," International Journal of Biology, Pharmacy and Allied Sciences, vol. 3, no. 11, pp. 2316-2332, 2014.

[72] D. Wu, W. Fan, A. Kishen, J. L. Gutmann, and B. Fan, "Evaluation of the antibacterial efficacy of silver nanoparticles against Enterococcus faecalis biofilm," Journal of Endodontics, vol. 40, no. 2, pp. 285-290, 2014.

[73] M. Samiei, M. Aghazadeh, M. Lotfi, S. Shakoei, Z. Aghazadeh, and S. M. Vahid Pakdel, "Antimicrobial efficacy of mineral trioxide aggregate with and without silver nanoparticles," Iranian endodontic Journal, vol. 8, no. 4, pp. 166-170, 2013.

[74] P. Mishra and S. Tyagi, "Surface analysis of gutta percha after disinfecting with sodium hypochlorite and silver nanoparticles by atomic force microscopy: an in vitro study," Dental research journal, vol. 15, no. 4, pp. 242-247, 2018.

[75] Y. Shantiaee, F. Maziar, O. Dianat, and F. Mahjour, "Comparing microleakage in root canals obturated with nanosilver coated gutta-percha to standard gutta-percha by two different methods," Iranian endodontic journal, vol. 6, no. 4, pp. 140145, 2011.

[76] V. Vishwanath and H. M. Rao, "Gutta-percha in endodonticsa comprehensive review of material science," Journal of conservative dentistry: JCD, vol. 22, no. 3, pp. 216-222, 2019.

[77] B. H. Baras, M. A. S. Melo, J. Sun et al., "Novel endodontic sealer with dual strategies of dimethylaminohexadecyl methacrylate and nanoparticles of silver to inhibit root canal biofilms," Dental Materials, vol. 35, no. 8, pp. 1117-1129, 2019.

[78] D. T. de Castro, C. do Nascimento, O. L. Alves, E. de Souza Santos, J. A. M. Agnelli, and A. C. dos Reis, "Analysis of the oral microbiome on the surface of modified dental polymers," Archives of Oral Biology, vol. 93, pp. 107-114, 2018.

[79] R. Pokrowiecki, T. Zareba, B. Szaraniec et al., "In vitro studies of nanosilver-doped titanium implants for oral and maxillofacial surgery," International Journal of Nanomedicine, vol. 12, pp. 4285-4297, 2017.

[80] W. Zhou, Z. Jia, P. Xiong et al., "Bioinspired and biomimetic AgNPs/gentamicin-embedded silk fibroin coatings for robust antibacterial and osteogenetic applications," ACS Applied Materials \& Interfaces, vol. 9, no. 31, pp. 25830-25846, 2017.

[81] A. Nozari, S. Ajami, A. Rafiei, and E. Niazi, "Impact of nano hydroxyapatite, nano silver fluoride and sodium fluoride varnish on primary teeth enamel remineralization: an in vitro study," Journal of Clinical and Diagnostic Research: JCDR, vol. 11, no. 9, pp. ZC97-ZC100, 2017. 